\title{
How Does Media Influence Social Norms? Experimental Evidence on the Role of Common Knowledge*
}

\author{
ERIC ARIAS
}

$H$ ow does media influence beliefs, attitudes, and behaviors? While many scholars have studied the effect of media on social and political outcomes, we know surprisingly little about the channels through which this effect operates. I argue that two mechanisms can account for its impact. Media provides new information that persuades individuals to accept it (individual channel), but also, media informs listeners about what others learn, thus facilitating coordination (social channel). Combining a field experiment with a plausibly natural experiment in Mexico, I disentangle these effects analyzing norms surrounding violence against women. I examine the effect of a radio program when it is transmitted privately versus when it is transmitted publicly. I find no evidence supporting the individual mechanism. The social channel, however, increased rejection of violence against women and increased support for gender equality, but unexpectedly increased pessimism about whether violence would decline in the future.

A central concern across social sciences has been to understand the extent to which mass communication can influence social and political outcomes. Indeed, many scholars have shown that media effects abound and cover a wide area of topics, anywhere from political support and electoral behavior up to the perpetration of violence. However, we know little about the underlying mechanisms behind these effects. That is, how is it that media influence beliefs, attitudes, and behaviors? In particular, how does media influence social norms?

The process underlying media influence can be broadly decomposed into two potential effects: (1) an individual or direct effect, and (2) a social or indirect effect. In the former, media provides information about new norms and persuades individuals to accept them (Bandura 1986; DellaVigna and Gentzkow 2010). In the latter, the information provided also serves as a coordination device. Coordination is needed because one can conceptualize social norms as coordination problems, that is, situations in which each person wants to participate only if others participate as well (Mackie 1996; Chwe 1998). As such, the provision of public information can enhance coordination on that norm through the creation of common knowledge (Mackie 1996; Chwe 2001).

While the individual mechanism would have an effect regardless of the dissemination method, the social one would be stronger when dissemination has a public component. Hence, I argue that information has a differential effect when it is transmitted individually and privately (e.g., through leaflets) than when it is transmitted through more social or collective outlets (such as mass media or public meetings). That is, how information is provided is important to fully

\footnotetext{
* Eric Arias, Postdoctoral Research Fellow at the Niehaus Center for Globalization and Governance, Princeton University, 432 Robertson Hall, Princeton, NJ 08544 (eric.arias@ @rinceton.edu). This research was carried out as part of a UNESCO Mexico program. the author especially thanks Samira Nikaein at the UNESCO Office in Mexico, Michael Gilligan and Cyrus Samii for their help and support. The author also thanks Michaël Aklin, Karisa Cloward, Livio Di Lonardo, Pat Egan, Jessica Gottlieb, Macartan Humphreys, Malte Lierl, Sera Linardi, Alan Potter, Peter Rosendorff, Shanker Satyanath, David Stasavage, Scott Tyson, participants at ISPS-Yale, WESSI-NYU Abu Dhabi, APSA, MPSA and PEIO for their suggestions and comments. All errors and interpretations are the author's alone and do not necessarily represent those of UNESCO. To view supplementary material for this article, please visit https://dx.doi.org/10.1017/psrm.2018.1
} 
understand the mechanisms behind its influence. Critically, however, media itself has a public component, and media related interventions in the literature have naturally been public. As such, by design, media is able to induce common knowledge precluding the isolation of the social component from the individual one, and thus making the task of fully understanding the microfoundations of media influence a daunting one.

This paper fills this gap by disentangling the extent to which media influence acts through the individual mechanism (via persuasion) versus the extent to which it does so through the social mechanism (via higher-order beliefs). To do so, I combine a plausibly natural experiment with a randomized field experiment, conducted in partnership with the UNESCO. Specifically, I analyze the effects of a norms campaign-a media (audio soap-opera) intervention-on a particular set of values and behaviors, namely attitudes and norms surrounding violence against women.

The issue of violence against women is an important and well-suited case for studying the influence of media. First, violence against women is a global concern. It is a violation of human rights and has extensive pernicious consequences that range from the direct physical and mental harm for women and their children to economic losses at the individual and national level. Second, in past years, development programs aimed at improving women's economic, political, and social status have attracted substantive attention from researchers and policy-makers alike. A particularly popular type of intervention has been media and social norms marketing campaigns, with a special emphasis on "edutainment" (e.g., Paluck and Green 2009). It is crucial to enhance our understanding of the mechanisms behind these policy interventions in order to improve their design and efficacy. Finally, the case of violence against women lends itself for studying the influence of media on social norms as existing evidence points to the link between them. Jensen and Oster (2009) show that the introduction of cable television in India exposed viewers to new information about the outside world and other ways of life, decreasing the reported acceptability of violence toward women. But this effect could also be explained by the publicity of the media, which can plausibly influence social norms via coordination-that is, influencing perceptions of what others think as desirable, and hence promote the rejection of violence because of the expectation that others will reject it as well.

The intervention manipulated the social context in which individuals were able to receive the program. To do so, the research was conducted in San Bartolomé Quialana, a small rural, indigenous community in Oaxaca, Mexico, during May to June 2013, where I combine (1) a plausible natural experiment on the broadcast's reach with (2) randomly assigned invitations to listen to the program. San Bartolomé Quialana is broadly representative of rural communities, where violence against women is a serious problem (UNESCO 2012). With these elements in mind, an audio soap-opera program designed to challenge norms of gender roles and, in particular, discourage violence against women, was broadcasted via the community loudspeaker. This particular loudspeaker had a special characteristic, however. Topography conditions affected its reach, precluding part of the community from accessing the broadcast. This is important because only the area outside the loudspeaker's reach provides the leverage to test the individual mechanism. Within this area, households were randomly invited to listen to the program, individually and privately, using an audio $\mathrm{CD}$ (Audio $C D$ treatment). Here, individuals were unaware of others listening to the program, precluding common knowledge creation and coordination, thus isolating the individual effect. On the other hand, the area within the loudspeaker's reach allows us to test the social mechanism. In this area, the program was broadcasted once such that households were able to listen to it (Village Loudspeaker treatment). In addition, households were randomly invited to listen to the program at a community meeting type of set-up. That is, they were invited to listen to the same program at the same time, but to 
TABLE $1 \quad$ Groups Created by the Research Design

\begin{tabular}{|c|c|c|}
\hline & Within the loudspeaker's reach & Outside the loudspeaker's reach \\
\hline $\begin{array}{l}\text { Invited to listen } \\
\text { (How?) } \\
\text { [Households/individuals } \\
\text { surveyed] }\end{array}$ & $\begin{array}{l}\text { I. Community meeting } \\
\text { (Public broadcast in common place) } \\
\text { [58/96] }\end{array}$ & $\begin{array}{l}\text { II. Audio CD } \\
\text { (Private audio CD) } \\
\text { [35/59] }\end{array}$ \\
\hline $\begin{array}{l}\text { Not invited } \\
\text { [Households/individuals } \\
\text { surveyed] }\end{array}$ & $\begin{array}{l}\text { III. Village loudspeaker (public broadcast) } \\
\text { [48/82] }\end{array}$ & $\begin{array}{l}\text { IV. Baseline } \\
\text { [60/103] }\end{array}$ \\
\hline
\end{tabular}

do it physically copresent with other members of the community (Community Meeting treatment). This treatment might facilitate the generation of common knowledge and, importantly, aims to match the invitation component of the Audio CD treatment. Overall, the design created four groups as shown in Table 1.

Measuring norms, attitudes, and behavior with a survey of 340 individuals in 200 households, I find that media influence is driven by social effects rather than individual persuasion. I also find that social interactions such as community meetings are not always necessary conditions for such effects. The evidence suggests that the social channel decreased personal and perceived social acceptance of violence against women and increased support for gender equality roles while also increasing pessimism on whether violence will decline in the future. In contrast, results show that the individual channel had no effect.

A competing explanation is that systematic differences may exist between the areas within and outside the loudspeaker's reach, which could potentially affect beliefs and behaviors related to violence against women. I argue that this is not the case and show that a battery of individual and household characteristics are balanced between the two areas. Given the small size of the town and the nature of the treatment conditions, another concern is that the design could have been vulnerable to spill-overs. However, as I further discuss below, the experiment was designed to address this issue to the greatest extent possible, and most importantly, the presence of spill-overs would bias against the findings of the paper.

This study joins the growing literature demonstrating that exposure to information provided by mass media can influence a wide range of attitudes and behaviors. This paper contributes to this literature by empirically distinguishing the individual and social effects of media influence. This is important for several reasons. First, it improves our understanding of the mechanisms via which media impacts attitudes and social norms; these estimates help resolve an extant puzzle in the empirical literature on media influence. Second, such estimates are critical for thinking about questions of policy interventions. Third, it also sheds light on the way media interventions may have pernicious or unintended effects.

\section{MEDIA AND THE MICROFOUNDATIONS OF SOCIAL NORMS CHANGE}

Norms are important because they are standards of behavior that are based on widely shared beliefs of how individual group members ought to behave in a given situation. As such, these customary rules of behavior coordinate individuals' interactions with others (Young 2008), and because of this, they are highly influential in shaping individual behavior, including discrimination and violence against a specific group, such as women. Norms can protect against violence, but they can also support and encourage the use of it. For instance, acceptance of violence is a risk factor for all types of interpersonal violence (Krug et al. 2002). 
Indeed, behavior and attitudes related to violence toward women are shaped and reinforced by social norms in general, and gender stereotypes and expectations within the society in particular. These norms persist within society because of individuals' preference to conform, given the expectation that others will also conform (Lewis 1969; Mackie 1996). That is, participation in such norms and behaviors (or the diffusion of new ones) is a coordination problem. This is because people are motivated to coordinate with one another when there are strategic complementarities: Social approval is only accrued by an individual if a sufficient number of people express their attitudes and behave in a similar way. Conversely, social sanctions can be inflicted on those with different expressed attitudes and behaviors if others do not join them (Coleman 1990). For instance, these sanctions can take the form of shaming, shunning, or any other form of social ostracizing (Paluck and Ball 2010). Other scholars argue that norms are self-sustaining irrespective of the threat of punishment. Two other mechanisms sustaining norms are (i) negative emotions such as guilt or shame that are triggered when norms have been internalized and (ii) the desire to avoid intrinsic costs that would result from coordination failure (Young 2008). In short, beliefs about the acceptability of a given behavior, such as violence against women, are a key factor in explaining their occurrence (Mackie 1996).

One might object that violence against women might be driven by different forces as it is often a private interaction in the household, and presumably people will not engage in violent acts simply because they think others do. But a person engaging in violence might often think about the overall social context. For instance, whether people who find out about these actions will understand it as a crime, and report it. Bancroft makes this point when discussing the psychology of abusive men as follows: "While a man is on an abusive rampage, verbally or physically, his mind maintains awareness of a number of questions: 'Am I doing something that other people could find out about, so it could make me look bad? Am I doing anything that could get me in legal trouble?"' (2003: 34). Furthermore, even if the physical consequences of domestic violence can be hide publicly, other behaviors surrounding gender inequality, such as early marriage or lack of financial independence, are more visible.

Because of these considerations, numerous policies and programs have embarked on ambitious campaigns to address social issues like violence against women by promoting changes in social norms. Many of these strategies take the form of media-driven information interventions, such as TV or radio soap operas (Paluck and Ball 2010). These efforts raise fundamental questions about the extent to and the conditions under which media can influence social norms in general, and about the microfoundations of such process in particular. Media influence can be broadly decomposed into two effects: (1) an individual or direct effect, and (2) a social or indirect effect.

\section{Individual Effect}

The individual or direct effect of media relies on persuasion. The emphasis is on the persuasive power of the content, which ignites an individual learning process, updating personal values and beliefs (Staub and Pearlman 2009; DellaVigna and Gentzkow 2010). This "individual educational process" is in line with arguments put forward by social learning theory, where the educational effect of media works via educational role models (Bandura 1986). These educational role models are able to perform an instructive function, and transmit knowledge, values and behaviors among others.

\section{Social Effect}

Media can also have an effect via a social mechanism. Here, media influence is rooted in the fact that it can provide information in a way that enhances coordination on a norm or action 
through the creation of common knowledge (Chwe 2001) This is because media's method of delivery is a public one. Information that is known to be publicly available helps individuals to form an understanding of their shared beliefs. Public information not only causes individuals to update their personal beliefs, but also allows them to update their beliefs about how widely these beliefs are shared (Morris and Shin 2002). That is, public information is used to know that others received the information, and that everyone who received the information knows that everybody else that received the information knows this, and so on, creating common knowledge. In this vein, some authors argue that "attempts to change public behaviors by changing private attitudes will not be effective unless some effort is also made to bridge the boundary between the public and the private" (Miller, Monin and Prentice 2000: 113).

Moreover, a social effect might be present even in the absence of an individual effect. That is, people might adjust their behavior and publicly expressed attitudes, but not necessarily their private beliefs. Such inconsistency between private and public is known as pluralistic ignorance, which describes situations in which most members of a group privately reject group norms, yet they believe that most members accept them (Miller and McFarland 1987). Such erroneous social inference facilitates a social effect in the absence of an individual effect.

Consequently, I argue that the method of dissemination is a significant driver of individuals' beliefs (and higher-order beliefs), and consequently, of their behavior. A public transmission of information-vis-à-vis a private one-facilitates the creation of common knowledge, thus increasing its influence on social norms. ${ }^{1}$ This is the main hypothesis of this paper:

HYPOTHESIS 1: (COMMON KNOWLEDGE). The effect of information on attitudes and norms is greater when the method of delivery is public.

A public method of dissemination helps bring about, but by no means guarantees, common knowledge, and coordinated action (Chwe 1998). Individuals might not know with certainty that others received the information, and thus everyone who received such information might not know with certainty that everybody else that received the information knows that others received the information, and so on. That is, a public promotion may nonetheless be affected by uncertainty surrounding higher-order beliefs. However, this uncertainty is influenced by the type of social interactions created by the conditions under which norms' promotion is received. In particular, certainty can be bolstered through face-to-face interactions, such as community meetings (Mackie 1996; Chwe 2001).

To address this heterogeneity within the public dissemination of information, I explore the extent to which different levels of uncertainty and potential social interactions moderate the diffusion of norms. Within the common knowledge framework, I analyze whether the publicness of the information is a sufficient condition for media influence and whether face-to-face interactions enhances such influence. That is, I disaggregate Hypothesis 1 into two secondary hypothesis:

HYPOTHESIS 2A: (PUBLIC SIGNAL). A public method of delivery is a necessary and sufficient condition for information to influence attitudes and norms (i.e., no social interaction is required).

\footnotetext{
1 Arguably, "strong" and "weak" hypotheses can be derived. The strong hypothesis would imply that only by increasing the publicness of the information above a certain threshold one should expect an effect, that is, a "tipping-point" argument (Finnemore and Sikkink 1998). The weak version would postulate that by increasing publicness one is able to increase the effect. Differentiating between these two is beyond the scope of this paper. See also Gottlieb (2015).
} 
HYPOTHESIS 2B: (FACE-TO-FACE). A public method of delivery of information with face-to-face interactions enhances the effect of information on attitudes and norms.

\section{UNESCO'S CAMPAIGN: A MEDIA INTERVENTION IN SAN BARTOLOMÉ QUIALANA}

To test these hypotheses, I conducted a media intervention in San Bartolomé Quialana, in partnership with the UNESCO Office in Mexico. San Bartolomé Quialana (or simply Quialana) is a small rural, indigenous community located in the state of Oaxaca. Its key features are broadly characteristic of rural municipalities in the rest of Mexico. (Section A1 provides further details.) For the purposes of this paper, an important aspect of Quialana is its cultural homogeneity. For example, as of 2010, out of the 2470 habitants, 2412 were born, and raised in Quialana. This is important because the ability to focus on a single community, holding cultural, and social aspects "constant," makes it easier to isolate the individual-level informational mechanisms that drive media influence on attitudes and social norms.

\section{The Soap-Opera}

The intervention consisted of an audio soap-opera designed to challenge gender role norms and discourage violence against women. Entitled Un nuevo amanecer en Quialana (A new dawn in Quialana) it was produced in conjunction with a regional partner non-governmental organization (NGO) and it included four episodes of $\sim 15$ minutes each, for a total running time of 57 minutes. The soap-opera was embedded in the local context, featuring common reference points such as "Tlacolula's market," as helping the audience to directly relate to the situations portrayed can increase its effect (La Ferrara, Chong and Duryea 2012). The plot evolved around a young couple who fell in love and started a family in Quialana. The narrative was developed such that the leading male character gradually transformed from a loving and caring husband to a violent and aggressive figure. Research shows that the male figure should not be displayed as a completely violent character from the outset so that listeners can create a rapport with him and not disregard his behavior as an exception (Singhal et al. 2003). Moreover, the language of the script used injunctive norms (Paluck and Ball 2010). For instance, instead of arguing "beating women is wrong" the soap-opera would say "citizens of Quialana believe that beating women is wrong." This actually biases against the main hypothesis of this paper because those in the Audio $C D$ treatment are exposed to these injunctive norms. One caveat of the narrative, however, is that it did not contain channel factors to act out these norms. ${ }^{2}$

Un nuevo amanecer en Quialana was broadcasted using the community loudspeaker as a special event: the premier of the first-ever locally produced soap-opera, and the first time the community loudspeaker was used for entertainment purposes.

\section{RESEARCH DESIGN}

The research design combines two sources of variation. Specifically, the social context in which people are able to receive the intervention is manipulated by (1) exploiting arguably exogenous variation generated by the topography of the community (i.e., within community variation of

\footnotetext{
${ }^{2}$ Channel factors are small but critical factors that facilitate or create barriers for behavior, for example, the promotion of a telephone hotline number that provides information and can refer callers to service providers (Singhal et al. 2003).
} 


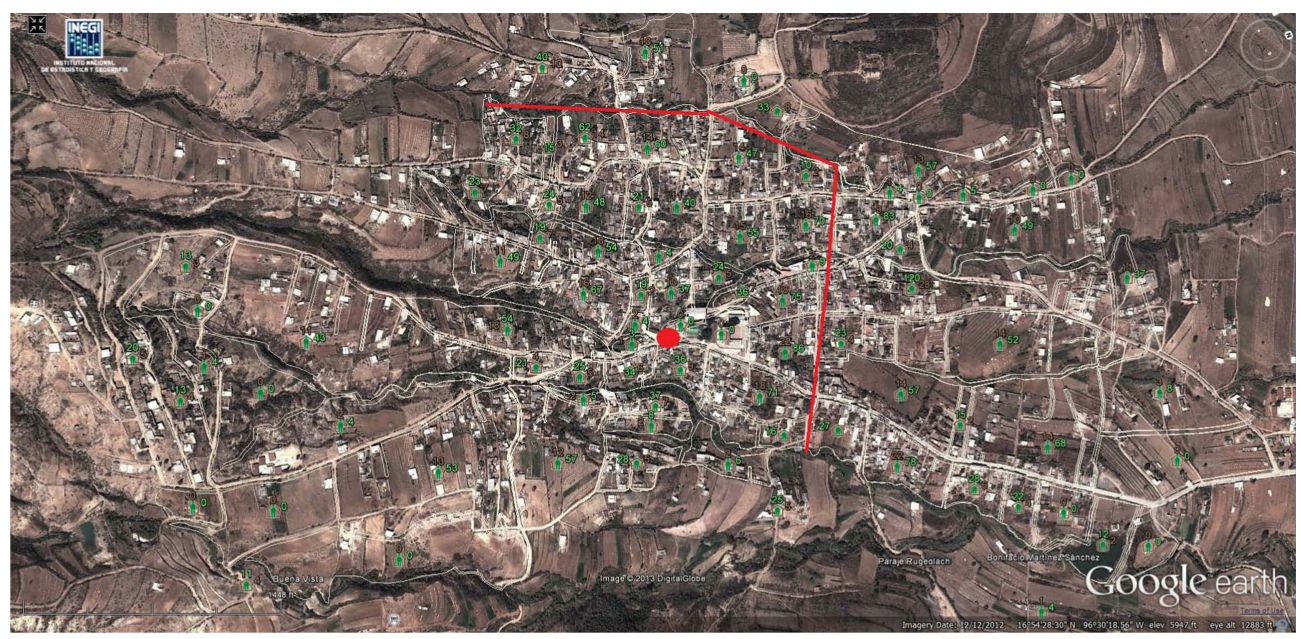

WITHIN THE LOUDSPEAKER'S REACH

OUTSIDE THE LOUDSPEAKER'S REACH

Fig. 1. San Bartolome Quialana and its loudspeaker's reach

Note: Population (green), households (brown). Red line: loudspeaker's reach. Red filled circle: Loudspeaker.

"broadcast access"), and (2) randomly inviting households to listen to the program. I further describe each one below.

\section{Natural Experiment: Loudspeaker, Topography, and Sound Check}

While Quialana did not have a local radio at the time of the intervention, it did posses a loudspeaker-located on top of the Town Hall, in the center of the community. Before the intervention, the loudspeaker primarily and only sporadically announced sales of small-scale household goods, such as construction materials, like bricks, or other livestock. It was never used for other announcements like news, weather, etc. Perhaps for these reasons the variation in the loudspeaker's reach (and it's sharpness) described below came as a surprise to many of our local partners who had previously taken for granted that nearly everyone in the community had access to the occasional announcements.

Leveraging variation in the loudspeaker's reach, I define two areas within Quialana: (1) the area within the loudspeaker's reach, and (2) the area outside the loudspeaker's reach. This within community variation is mainly a product of topography conditions. For example, from one end of the municipality to the other there is an altitude difference of more than $500 \mathrm{ft}$. More specifically, in some areas, the slopes become high enough that they preclude the sound to travel with clarity. ${ }^{3}$ That is, the source of variation is not a function of distance to the loudspeaker per se, but mainly of altitude difference. That is, two households can be located at the same distance from the loudspeaker and still one of them can fall within the loudspeaker's reach and not the other. Figure 1 shows the loudspeaker's reach, which was determined via a sound-check process from the ground (further explained in Section A2).

\section{Balance}

A valid concern is that systematic differences may exist between these two areas, which could potentially be correlated with attitudes and norms related to violence against women. One of the

\footnotetext{
${ }^{3}$ For examples, see Figures A2 and A3.
} 
advantages of conducting the study within a single, small (slightly more than a mile long) community is precisely being able to leverage the cultural homogeneity and ameliorate concerns about such potential differences. Based on informal and formal discussions with UNESCO personnel, NGO partners, and citizens of Quialana there is no qualitative evidence of sorting into one area or another based on attitudes and behavior related to gender inequality. Qualitative analyses and focus groups organized by UNESCO suggested that violence was widespread equally across the community (UNESCO 2012). I complement these on-the-ground accounts with quantitative evidence. Specifically, I rely on data from the 2012 National Housing Inventory to show that a battery of individual and household characteristics are balanced between the two areas (Table A2).

While the focus on a very small community, alongside the qualitative and quantitative evidence strengthens the plausibility of the natural experiment, such interpretation might be threatened if unobservables linked to each of the two areas are also linked with attitudes and behaviors towards women. This should be taken into account when interpreting the results.

\section{Randomization: Audio CD and Community Meeting}

Within each area, households were randomly invited to listen to the soap-opera via systematic sampling with a random start, creating the Community Meeting and Audio CD treatments. Here, the experiment was able to hold the content of the media program constant while varying the social context in which it was received. In the area within the loudspeaker's reach, households were invited to listen to the program in the cafeteria next to the Municipal building (i.e., Community Meeting). In the area outside the loudspeaker's reach, households were invited to listen to it in their homes using an audio CD (i.e., Audio $C D$ treatment). The regional partner NGO served as the public face of the treatments, presented as part of an initiative to create a local radio station and as such, there was no mention of UNESCO's involvement.

To test the individual mechanism, the invitation to listen to the soap-opera (via the audio CD) had to be privately delivered to the household. Here, caution was taken to prevent households from believing that other households were also receiving the program—although as argued before, this would bias against my hypotheses. Enumerators were trained to keep away from sight any material that would signal that other households were also being approached. Further, when reaching out to the household, enumerators emphasized that the audio CD was a pilot program, arguably a one-time opportunity to preview it and provide feedback. While not explicitly saying that the household was the only one selected to receive the audio (to avoid deception), enumerators were trained to hint at that possibility and to frame such opportunity as something very novel, exclusive and private-which might explain the perfect level of compliance. As such, audio CDs were handed out along with a short questionnaire meant as a listening-check device: the enumerator would leave the audio CD and questionnaire sheet and then stop by a couple of hours later to pick up the sheet, and based on this, compliance was 100 percent ${ }^{4}$. Because of this set-up and based on comments from enumerators, in some cases all family members were present at the time and reportedly all listened to it, but in other cases not every household member was present at the time, and hence did not listen to it.

To test the social mechanism, the design created a comparable treatment group, the Community Meeting, where the invitation to listen the soap-opera matches the invitation

\footnotetext{
${ }^{4}$ Almost all households played the audio CD on their own stereo systems, and when they did not have one, enumerators would offer to lend "their personal" portable CD player. The questionnaire consisted on rating the soap-opera, asking the name of the character with whom they identified the most, and providing space for comments.
} 
component of the Audio CD treatment. Moreover, the Community Meeting provides leverage to explore the effects of public information. By creating a very particular form of social interaction (or at least the knowledge about it), namely the community meeting, this treatment might increase the level of certainty individuals' have about others receiving the information, and so on. At the same time, this common knowledge mechanism might be confounded by other potential interactions facilitated by the meeting, such as deliberation. To be clear, during the community meeting there was no deliberation (out of respect to other listeners, conversations were not allowed). However, deliberation and exchange of opinions could have occurred after the meeting. Inasmuch these interactions are indeed facilitated by the creation of common knowledge, the design is able to disentangle the social and individual mechanisms of media influence (however, it cannot unbundle face-to-face certainty from deliberation). Finally, people from roughly one in four households invited to the Community Meeting actually went to the cafeteria - that is, complied with the Community Meeting treatment. Anecdotally, during the broadcast people did stop by the Town Hall, just outside the cafeteria where the community meeting was taking place, and listen to the soap-opera (or a least parts of it) from just outside. Other accounts point to the fact that many simply listened to the soap-opera from their own houses.

However, to fully understand the social mechanism, I explore whether the public transmission of information is a sufficient condition to influence norms as well the extent to which the face-to-face interactions can enhance the effect on norms. To potentially address this, the design created a public treatment without imposing such social interactions: households who were able to listen to the broadcast by being within the loudspeaker's reach but were not in the Group condition constitute the Village Loudspeaker treatment.

Finally, households outside the loudspeaker's reach who did not receive the audio CD represent the baseline group. These four conditions are summarized in Table 1.

An unbiased estimation of the mechanisms relies on two dimensions: one, facilitating the creation of common knowledge in the social conditions, and two, precluding it in the individual condition (i.e., no spill-overs). First, for the broadcast to facilitate the creation of common knowledge, it should be the case that people who listens to it know that other people are hearing it too. This is less of a concern in the Community Meeting treatment because information is explicitly given to the household, so they know that others are also receiving the invitation, and so on. However, a person in the Village Loudspeaker treatment might believe that she has heard the broadcast, say because she lives close to the Town Hall or because she believes she has particularly good hearing but that few of her neighbors actually have heard it. I attempt to address this in two ways. First, I include distance to the Town Hall as a control covariate in the empirical analysis. This variable is also a relevant covariate inasmuch it also works as a proxy for population density, which might be a potential confounder with respect to the perpetration of violence. Second, as discussed below, the empirical strategy relies on the estimation of intention-to-treat effects (ITT) precisely because individuals might fail to comply with the treatment - in the case of the Village Loudspeaker, individuals might not listen to the program nor realizing that others are listening to it as well, and so on. As such, it represents a conservative or lower bound estimation.

The second dimension is linked to the notion that those who receive the individual treatment should be unaware of other treatments. Given the small size of the town and the nature the treatment conditions, the design was vulnerable to spill-overs. However, such spill-overs would bias against the main hypothesis of the paper. This is because those in the individual condition might find out that other people were also receiving the soap-opera. Nevertheless, in order to minimize potential spill-overs, invitations for the Community Meeting were given out on a 
Friday. Both treatments were administered the next day: the Audio $C D$ treatment was conducted on Saturday-starting early in the morning, and the Village Loudspeaker and Community Meeting broadcast was also implemented on Saturday, during the evening.

Similarly, the design faced a trade-off between minimizing these spill-over concerns and maximizing the intensity of the treatment. For the former, the ideal was to minimize the time between the treatments and the survey. For the latter, an alternative was to implement a weekly soap-opera over several weeks or months. Given that the main goal of this study was to analyze the underlying mechanisms of media influence, I prioritized addressing the spill-over concerns at the expense of a limited intensity of the treatment. Nonetheless, experiments where only one day or even 1-hour interventions were implemented have found profound effects (e.g., Ravallion et al. 2015). Given these considerations, the norm intervention was implemented as a one-day event only, and the surveys were administered over the following few days.

\section{Outcome Measurement}

The regional partner NGO also served as the public face of the survey, presented as a mean to retrieve the opinion of Quialana citizens to inform an initiative for starting a community radio. ${ }^{5}$ In the survey, three questions measured respondents' beliefs and estimation of others' beliefs and actions with respect to violence against women, and three other questions measured attitudes and individual actions related to it. Hence, I evaluate six outcomes of interest, which I describe in detail below.

The first dependent variable is a measure of Personal beliefs aimed at capturing the extent to which people believe and are willing to state that violence against women is a recurring problem in the community. The question asked was "Do you think that violence against women is something that happens here in Quialana?" and it was coded from 1 ("No, this never happens here in Quialana") to 5 ("This happens too much in Quialana"). Given the qualitative evidence that violence is pervasive in Quialana (UNESCO 2012). This item was designed not to capture such factual scenario, but instead the respondent's personal beliefs about the desirability of (and hence, willingness to expose) certain actions. In other words, the intuition behind this question is to capture the shift from a perception where "husbands are never violent to their wives-they might engage in some aggressive behavior but that is not violence" to a situation in which "that" type of behavior is recognized as violence, and moreover, it is socially appropriate to judge it as serious problem.

The second variable of interest captures the Perceived social rejection. That is, the extent to which an individual believes that the community believes violence is a problem. The question was "Do you think that that the community, the neighbors, and other families see violence against women as a serious problem here in Quialana?" with responses coded from 1 ("No, they do not see it as a problem at all") to 4 ("They see it as a serious problem that needs to change"). As in the previous question, this item aims to measure the shift in norm perception from a norm where violence is tolerated (e.g., the community experiences violence but sees it a routine and excusable) to a norm where violence is rejected.

The third variable, Expectations about the future, measures individual expectations that this type of violence will decline in the future. The question was "Do you think the next generation of Quialana males ...?" with answers being coded from 1 ("Will abuse women more") to 4 ("Will never abuse women"). That is, higher values represent more optimistic views about the future.

\footnotetext{
${ }^{5}$ Surveys were collected at the respondents' households from June 3 to June 5.
} 
While these three measures are able to retrieve individuals' perception about norms surrounding violence against women, they do not directly measure individual attitudes, beliefs, nor actions regarding gender roles or domestic violence. Outcomes four through six address this, including a behavioral outcome embedded in the survey.

The fourth outcome, Value Transmission, measures the extent to which the respondent would educate a child with gender equality values. This captures the parents' decisions concerning which values to inculcate in their children, which are affected by perceived prevailing values in the society (Tabellini 2008). In particular, it focuses on attitudes toward equality regarding household chores, which is seen by many as one of the key challenges for achieving gender equality (World Bank 2012). The question was "Would you educate your child so that domestic chores, such as doing laundry and cooking, are as much a responsibility of the men as they are of the women?," with the answer being coded 1 if the respondent supports this type of education, 0 otherwise.

The fifth variable captures the individual Reaction to an episode of violence. The question was "If you see or hear a neighbor's wife being beaten by her husband, what would you do?." Responses are collapsed into a binary variable in the following way: Reaction to violence takes a value of 1 if the respondents answers that they would interrupt the couple so to stop the violence and/or call the police so they intervene, and is coded 0 if the answer implies that they would not take any action at the moment. ${ }^{6}$

The sixth variable retrieves a behavioral outcome. Survey respondents were asked if they would sign a petition to support the creation of a violence against women support group: the variable Petition signature is coded 1 if they signed the petition, 0 otherwise.

To account for multiple testing I also analyze an Index variable created using standardized inverse-covariance-weighted (ICW) averages of the previous variables. The scale of the resulting index is in control group standard deviations, and higher values can be interpreted as higher levels of rejection and perceived rejection of violence against women and increased support for gender equality.

Three key covariates were collected, namely gender, age, and education. A total of 200 households were surveyed; this represents about one in every three households in Quialana. When available, both the male and female heads of the households were surveyed. This generated a maximum of 340 observations. Table A8 shows descriptive statistics and Section A4 shows randomization checks.

\section{EMPIRICAL STRATEGY}

The empirical strategy relies on estimating ITT effects. In this particular set-up, however, the invitation to the Community Meeting (i.e., the assignment to treatment) matches the theoretical motivation behind the treatment itself. That is, the invitation provides specific information about how the soap-opera is going to be disseminated (i.e., there will be a broadcast and an event where people are able to receive the program together), thus facilitating the creation of common knowledge. This also has implications for estimating local average treatment effects (LATE) as it may be read as a violation of the exclusion restriction-this precludes an unbiased estimation of the LATE, providing further reasons to focusing on the ITT estimation.

\footnotetext{
${ }^{6}$ Answers that take the value of 1 are of the type "call the police" and/or "interrupt them to stop it," while answers coded 0 are "do nothing, because it's a private matter between husband and wife" or "do nothing at the moment, but ask what happened later."
} 
I conduct the analysis using ordinary least squares, with two empirical strategies, namely (1) Community Meeting versus Audio CD and (2) all four treatment conditions. ${ }^{7}$

\section{Social and Individual Mechanisms: Community Meeting Versus Audio CD}

The first empirical strategy focuses on testing the Community Meeting and Audio CD treatments against each other, as follows:

$$
Y_{i, h}=\phi+\alpha \text { Community Meeting }{ }_{h}+\mathbf{X}_{i, h}^{\prime} \theta+\epsilon_{i, h},
$$

where $i$ indexes individuals and $h$ households; $Y_{i, h}$ represents the outcomes of interests aforementioned (continuous variables are expressed in standard deviations of the distribution of responses in the Audio CD condition); Community Meeting is an indicator for whether the household was invited to the meeting. In this estimation, those in the Audio $C D$ treatment-that is, living outside the loudspeaker's reach and invited to listen to the audio CD-constitute the baseline category. For efficiency, I include a vector of controls, $\mathbf{X}_{i, h}^{\prime}$, which consist of an indicator for Female gender, respondent's Age, and Education which denotes a schooling indicator for whether the respondent (1) never attended school, (2) attended but did not finish primary school, or (3) finished primary school. I also control for the natural logarithm of the Distance in meters between the household and the Town Hall. Having assigned treatments to households, I cluster the standard errors at the household-level.

The coefficient of interest in Equation 1 is $\alpha$; it captures the social mechanism underlying norms diffusion. Hypothesis 1 predicts $\alpha>0$. Nonetheless, I test it with a two-sided test.

\section{All Treatment Conditions: Full Sample}

The estimates of the Community Meeting are able to isolate the social effects induced by common knowledge. However, they might be influenced by the increased certainty created by the face-to-face interaction, and might potentially be confounded by other social interactionsfacilitated by the community meeting-such as deliberation. To address this and understand the extent to which a public method of delivery is a sufficient condition to influence norms, I rely on the full sample, as follows:

$Y_{i, h}=\phi+\alpha$ Community Meeting $_{h}+\gamma$ Village Loudspeaker ${ }_{h}+\beta$ Audio $\mathrm{CD}_{h}+\mathbf{X}_{i, h}^{\prime} \theta+\epsilon_{i, h}$

where $Y_{i, h}$ represents the outcomes (continuous variables are expressed in standard deviations of the distribution of responses in the baseline condition). The vector of controls, Community Meeting and Audio CD are defined as before. VillageLoudspeaker is an indicator for whether a household is within the loudspeaker's reach but was not invited to the meeting. Finally, those living in the individual area without treatment represent the baseline category.

In Equation 2, the coefficients of interest are $\alpha, \beta$, and $\gamma$. They measure the effect of the intervention and, by design, can shed light on the different potential mechanisms. Here, Hypothesis 1 predicts $\alpha>\beta$ and $\gamma>\beta$, and more specifically, Hypothesis 2a predicts $\gamma>0$ while Hypothesis $2 \mathrm{~b}$ predicts $\alpha>0$ with $\alpha>\gamma$.

\footnotetext{
${ }^{7}$ Results using logistic models are substantially the same (see Online Appendix).
} 
RESULTS

\section{Community Meeting Versus Audio CD}

Table 2 displays the results for each outcome of interest using two different specifications. The first one displays a specification using only the Community Meeting indicator (i.e., $\alpha$ ), while the second one includes the vector of control covariates.

Results regarding to the influence on personal beliefs suggest that those invited to the community meeting were more likely than those invited to the Audio CD to state that violence against women is a recurring problem in Quialana. The parameter estimate gains precision when introducing controls but remains stable ranging from 0.33 to $0.35 \mathrm{SD}$ relative to the Audio $\mathrm{CD}$ condition ( $\mathrm{p}$-value $=0.065$ and $\mathrm{p}$-value $=0.052$, respectively).

When looking at the perceived social rejection, the evidence points in the same direction, with stable (0.66 and 0.65$)$ and precise estimates.

The community meeting effects on expectations about the future are negative, very stable $(-0.48$ and -0.42$)$ and statistically significant at conventional levels, suggesting that those invited to the meeting became more pessimistic about the decrease of violence in the future. This arguably perverse effect could be explained by several factors. One explanation might be that, while the community meeting induced coordination around a new injunctive norm (i.e., people in Quialana should reject violence) it also raised awareness and facilitated coordination around a more subtle descriptive norm, namely that violent behavior is prevalent in the community. This more precise belief about the current situation of the community, coupled with the fact that the soap-opera did not offer any channel factors to act upon it, might have induced pessimistic expectations for the future extent of violence. Another explanation is that, as a result of the new common knowledge, individuals may foresee an increase opposition to violence against women, which in turn may potentially lead to a backlash effect. For instance, more women may speak out and oppose violence, creating a more violent response from a subset of men. While the data does not allow me rule out or pin down a particular explanation, it nonetheless shows that this effect is driven by a social mechanism.

The analyses of individual actions also support the social mechanism. Those invited to the community meeting were 16 percentage points more likely (Model 8) than those invited to the Audio CD to say they would educate their children on gender equality values, 20 percentage points more likely to react to a violent event (Model 10), and 20 percentage points more likely to sign the petition (Model 12).

The ICW Index analysis confirm these results. Subjects invited to the community meeting have an index of responses $0.45 \mathrm{SD}$ higher than those invited to the Audio CD.

To address concerns about the plausibility of the natural experiment, Table A11 replicates the analysis restricting the sample to households within $300 \mathrm{~m}$ of the Town Hall, finding similar results.

The overall evidence is clear. Media influence, captured by changes in beliefs, attitudes, and behavior, is primarily driven by a social channel. However, creating common knowledge might also facilitate a more precise belief of the status quo, thus setting negative expectations about future change, as suggested by the evidence on beliefs about the future prevalence of violence.

\section{All Treatment Conditions}

Table 3 displays the results for the full sample, without and with controls.

The analyses on personal and perceived social rejection show that the informational effects on beliefs and norms are driven entirely by the social mechanisms. When analyzing the 
table 2 Community Meeting Versus Audio CD

\begin{tabular}{|c|c|c|c|c|c|c|c|c|c|c|c|c|c|c|}
\hline & \multicolumn{2}{|c|}{ Personal Beliefs } & \multicolumn{2}{|c|}{ Perceived Rejection } & \multicolumn{2}{|c|}{ Expectation on Future } & \multicolumn{2}{|c|}{ Value Transmission } & \multicolumn{2}{|c|}{ Reaction to Violence } & \multicolumn{2}{|c|}{ Petition Signature } & \multicolumn{2}{|c|}{ Index (ICW) } \\
\hline & (1) & (2) & (3) & (4) & (5) & (6) & (7) & (8) & (9) & (10) & (11) & (12) & (13) & (14) \\
\hline Community & $\begin{array}{r}0.33^{+} \\
(018)\end{array}$ & $\begin{array}{r}0.35^{+} \\
0.18\end{array}$ & $0.66 * *$ & $0.65^{* *}$ & $-0.48^{*}$ & $-0.42^{*}$ & $0.13^{+}$ & $0.16^{*}$ & $0.15^{*}$ & $0.20^{* *}$ & $0.16^{+}$ & $0.20^{*}$ & $0.39^{*}$ & $0.50^{* *}$ \\
\hline$N$ & 154 & 150 & 154 & 150 & 154 & 150 & 150 & 146 & 153 & 149 & 141 & 137 & 137 & 133 \\
\hline Households & 94 & 91 & 94 & 91 & 94 & 91 & 94 & 90 & 94 & 91 & 92 & 88 & 92 & 88 \\
\hline & 0.03 & 0.06 & 0.11 & 0.11 & 0.06 & 0.09 & 0.04 & 0.10 & 0.05 & 0.12 & 0.03 & 0.16 & 0.05 & 0.16 \\
\hline Covariates & & $\checkmark$ & & $\checkmark$ & & $\checkmark$ & & $\checkmark$ & & $\checkmark$ & & $\checkmark$ & & $\checkmark$ \\
\hline
\end{tabular}

Note: Standard errors clustered at the household level in parentheses.

Covariates: age, female, education, distance.

ICW $=$ inverse-covariance-weighted.

${ }^{+} \mathrm{p}<0.10, * \mathrm{p}<0.05, * * \mathrm{p}<0.01$. 
TABLE 3 All treatment conditions.

\begin{tabular}{|c|c|c|c|c|c|c|c|c|c|c|c|c|c|c|}
\hline & \multicolumn{2}{|c|}{ Personal Beliefs } & \multicolumn{2}{|c|}{ Perceived Rejection } & \multicolumn{2}{|c|}{ Expectation on Future } & \multicolumn{2}{|c|}{ Value Transmission } & \multicolumn{2}{|c|}{ Reaction to Violence } & \multicolumn{2}{|c|}{ Petition Signature } & \multicolumn{2}{|c|}{ Index (ICW) } \\
\hline & (1) & (2) & (3) & (4) & (5) & (6) & (7) & (8) & (9) & (10) & (11) & (12) & (13) & (14) \\
\hline Community & $0.29^{+}$ & $0.29^{+}$ & $0.64 * *$ & $0.63 * *$ & $-0.24^{+}$ & -0.23 & $0.10^{+}$ & $0.09^{+}$ & $0.14 * *$ & $0.14 * *$ & $0.18 *$ & $0.16^{*}$ & $0.34 *$ & $0.35 *$ \\
\hline Meeting $(\alpha)$ & $(0.15)$ & $(0.15)$ & $(0.16)$ & $(0.18)$ & $(0.14)$ & $(0.16)$ & $(0.05)$ & $(0.05)$ & $(0.05)$ & $(0.05)$ & $(0.07)$ & $(0.07)$ & $(0.16)$ & $(0.15)$ \\
\hline Village & $0.45^{* *}$ & $0.42 * *$ & $0.40 *$ & $0.43 *$ & $-0.20^{+}$ & $-0.20^{+}$ & 0.06 & 0.03 & $0.12 *$ & $0.10^{+}$ & 0.06 & 0.01 & 0.24 & 0.19 \\
\hline Loudspeaker $(\gamma)$ & $(0.16)$ & $(0.16)$ & $(0.19)$ & $(0.19)$ & $(0.12)$ & $(0.12)$ & $(0.06)$ & $(0.06)$ & $(0.06)$ & $(0.06)$ & $(0.07)$ & $(0.07)$ & $(0.16)$ & $(0.14)$ \\
\hline Audio & -0.08 & -0.10 & -0.13 & -0.14 & 0.20 & 0.17 & -0.04 & -0.06 & -0.01 & -0.04 & 0.02 & -0.03 & -0.05 & -0.12 \\
\hline $\operatorname{CD}(\beta)$ & $(0.20)$ & $(0.20)$ & $(0.20)$ & $(0.21)$ & $(0.17)$ & $(0.18)$ & $(0.07)$ & $(0.07)$ & $(0.08)$ & $(0.08)$ & $(0.08)$ & $(0.08)$ & $(0.20)$ & $(0.18)$ \\
\hline$N$ & 335 & 327 & 335 & 327 & 335 & 327 & 329 & 320 & 336 & 327 & 315 & 307 & 304 & 298 \\
\hline Households & 200 & 197 & 200 & 197 & 200 & 197 & 200 & 196 & 200 & 197 & 198 & 194 & 197 & 193 \\
\hline$R^{2}$ & 0.05 & 0.06 & 0.08 & 0.08 & 0.04 & 0.04 & 0.02 & 0.07 & 0.04 & 0.10 & 0.02 & 0.10 & 0.03 & 0.11 \\
\hline Covariates & & $\checkmark$ & & $\checkmark$ & & $\checkmark$ & & $\checkmark$ & & $\checkmark$ & & $\checkmark$ & & $\checkmark$ \\
\hline$F$-test $\alpha<\beta$ & 0.03 & 0.03 & 0.00 & 0.00 & 0.99 & 0.99 & 0.02 & 0.00 & 0.03 & 0.01 & 0.03 & 0.01 & 0.02 & 0.00 \\
\hline$F$-test $\gamma<\beta$ & 0.00 & 0.01 & 0.01 & 0.01 & 0.99 & 0.99 & 0.04 & 0.03 & 0.10 & 0.11 & 0.31 & 0.32 & 0.06 & 0.04 \\
\hline$F$-test $\alpha<\gamma$ & 0.85 & 0.80 & 0.11 & 0.16 & 0.63 & 0.58 & 0.33 & 0.21 & 0.24 & 0.10 & 0.07 & 0.02 & 0.24 & 0.14 \\
\hline
\end{tabular}

Note: Standard errors clustered at the household level in parentheses.

Covariates: age, female, education, distance.

ICW $=$ inverse-covariance-weighted.

${ }^{+} \mathrm{p}<0.10,{ }^{*} \mathrm{p}<0.05, *{ }^{*} \mathrm{p}<0.01$. 
expectations about the future, the estimated parameters for social treatments are similar in size, ranging from 0.20 to 0.24 , and once again showing a negative sign. In contrast, the Audio CD parameters are positive but far from statistically significant.

These first set of results support both the community meeting and Village Loudspeaker treatments. While the analyses of individual attitudes and actions also support the social mechanism, the evidence is stronger for the community meeting-supporting Hypothesis $2 \mathrm{~b}$. A similar pattern emerges when analyzing the ICW Index.

Additionally, I estimated several $F$-test of inequality of coefficients. When comparing either one of the social conditions to the Audio $\mathrm{CD}(\beta)$, they tend to show a statistically significant difference at conventional levels, supporting Hypothesis 1. When pushing further the analysis of the social mechanism, the evidence shows that publicness in and of itself can be a sufficient condition to diffuse norms, in favor of Hypothesis 2a. Nonetheless, some of the evidence also suggests that face-to-face interactions can indeed enhance such effect, providing some support for Hypothesis $2 b$.

As before, I replicate the analysis by analyzing households within $300 \mathrm{~m}$ from the Town Hall, finding the same results (Table A12).

Overall, these findings again suggest that social mechanisms are the main drivers behind media influence on attitudes and norms.

\section{DISCUSSION}

A valid concern when interpreting the results is the extent to which they represent a one-off case in a unique setting. As noted before, in many aspects, Quialana is similar to many other municipalities in Mexico as a community with high levels of media consumption and issues with gender inequality and violence against women. Similarly, as a large and diverse society aiming to empower women so to overcome social challenges, Mexico has much in common with other developing and even developed countries. (See Section A6 for a more detailed discussion.) Yet, to what extent are the results from this study externally valid in the sense that they generalize beyond Quialana? While there are numerous variations in context or treatment design that could change the estimates presented here, the results nonetheless speak to a plausibly phenomenon; the notion that public information, via common knowledge and coordination, can induce differences in norms and behavior is often stated as a general proposition instead of stated as applying to a particular context (Chwe 2001).

Three particular results merit further exploration. First, the negative results on expectations about the future was arguably surprising. Further understanding the conditions under which these type of backlashes occur and can be precluded (e.g., emphasizing channel factors) is theoretically and policy relevant. Second, the mixed results on the Village Loudspeaker point to the need for more inquiry into the conditions under which public information is a sufficient condition to influence norms and the conditions under which securing common knowledge via social interactions is actually necessary. Third, the Audio CD results suggest that private persuasion in this context was ineffective. From the point of view where social norms are deeply embedded in a community, this result is arguably not surprising precisely because it does not have such link with the community. However, it might also be specific to the issue at handperhaps, in less sensitive issue areas, where social pressures might carry relative less weight, individual persuasion might be more effective.

Finally, there are potential concerns about whether the changes in reported attitudes, represent changes in behaviors, or just in reporting. Despite the behavioral evidence on the petition signature, one may be still concerned that public treatments only change what 
respondents think other people want to hear and see about the acceptability of violence, but does not actually change the incidence of abuse. Without directly observing people in their homes, however, it is difficult to conclusively separate changes in reporting from changes in behavior. However, if media interventions only change what is reported, it still represents social norms change and progress. Changing social norms is a necessary (Jensen and Oster 2009) and can be sufficient step toward changing the desired outcomes (Mackie 1996).

\section{CONCLUSION}

It is well know that exposure to information provided by the media outlets can influence a wide range of attitudes and behavior. However, less is known about the specific mechanisms behind such influence. Two broad mechanisms can account for such effects, namely an individual mechanism based on persuasion and a social mechanism based on higher-order beliefs and coordination. This paper examines these mechanisms and disentangles their effects at the individual level, studying attitudes, and norms toward violence against women.

The evidence presented here shows a very consistent story: media influence on attitudes and social norms is driven mainly by social effects rather than individual persuasion. First, I show that a public method of delivery was able to decrease personal and perceived social acceptance of violence against women and increased support for gender equality roles, whereas a private delivery had no discernible effects. I also show that public information is no panacea as it also increased pessimism on whether violence will decline in the future. Second, I present evidence that a pure public method of delivery (i.e., without social interactions) can be a necessary and sufficient condition to influence attitudes and norms.

Overall, further understanding the interaction between individual beliefs and different types and sources of information can shed light on the social mechanism purported here.

\section{REFERENCES}

Bancroft, Lundy. 2003. Why Does He Do That? Inside the Minds of Angry and Controlling Men. New York, NY: Berkley Books.

Bandura, Albert. 1986. Social Foundations of Thought and Action: A Social Cognitive Theory. Englewood Cliffs, NJ: Prentice-Hall.

Chwe, Michael. 1998. 'Culture, Circles, and Commercials: Publicity, Common Knowledge, and Social Coordination'. Rationality and Society 10:47-75.

Chwe, Michael. 2001. Rational Ritual: Culture, Coordination, and Common Knowledge. Princeton, NJ: Princeton University Press.

Coleman, James. 1990. Foundations of Social Theory. Cambridge, MA: Harvard University Press.

DellaVigna, Stefano, and Matthew Gentzkow. 2010. 'Persuasion: Empirical Evidence'. Annual Review of Economics 2:643-69.

Finnemore, Martha, and Kathryn Sikkink. 1998. 'International Norm Dynamics and Political Change'. International Organization 52(4):887-917.

Gottlieb, Jessica. 2015. 'Common Knowledge and Voter Coordination: Experimental Evidence from Mali'. In André Blais, Jean-Francois Laslier and Karine Van der Straeten (eds), Voting Experiments, 89-113. New York, NY: Springer Press.

Jensen, Robert, and Emily Oster. 2009. 'The Power of TV: Cable Television and Women's Status in India'. Quarterly Journal of Economics 124(3):1057-094.

Krug, Etienne, Linda Dahberg, James Mercy, Anthony Zwi, and Rafael Lozano. 2002. World Report on Violence and Health. Geneva: WHO.

La Ferrara, Eliana, Alberto Chong, and Suzanne Duryea. 2012. 'Soap Operas and Fertility: Evidence from Brazil'. American Economic Journal: Applied Economics 4(4):1-31. 
Lewis, David. 1969. Convention: A Philosophical Study. Cambridge, MA: Harvard University Press.

Mackie, Gerry. 1996. 'Ending Footbinding and Infibulation: A Convention Account'. American Sociological Review 61(6):999-1017.

Miller, Dale, Benoit Monin, and Deborah Prentice. 2000. 'Pluralistic Ignorance and Inconsistency Between Private Attitudes and Public Behaviors'. In Deborah Terry and Michael Hogg (eds), Attitudes, Behavior, and Social Context: The Role of Norms and Group Membership, 95-113. New York, NY: Lawrence Erlbaum Associates.

Miller, Dale, and Cathy McFarland. 1987. 'Pluralistic Ignorance: When Similarity is Interpreted as Dissimilarity'. Journal of Personality and Social Psychology 53:298-305.

Morris, Stephen, and Hyun Song Shin. 2002. 'Social Value of Public Information'. American Economic Review 92(5):1521-534.

Paluck, Elizabeth, and Donald Green. 2009. 'Deference, Dissent, and Dispute Resolution: An Experimental Intervention Using Mass Media to Change Norms and Behavior in Rwanda'. American Political Science Review 103(4):622-44.

Paluck, Elizabeth, and Laurie Ball. 2010. Social Norms Marketing Aimed at Gender Based Violence: A Literature Review and Critical Assessment. New York: International Rescue Committee.

Ravallion, Martin, Dominique van de Walle, Puja Dutta, and Rinku Murgai. 2015. 'Empowering Poor People Through Public Information? Lessons From a Movie in Rural India'. Journal of Public Economics 132:13-22.

Singhal, Arvind, Michael Cody, Everett Rogers, and Miguel Sabido (eds) 2003. Entertainment-Education and Social Change: History, Research, and Practice. New York, NY: Routledge.

Staub, Ervin, and Laurie Pearlman. 2009. 'Reducing Intergroup Prejudice and Conflict: A Commentary'. Journal of Personality and Social Psychology 96(3):588-93.

Tabellini, Guido. 2008. 'The Scope of Cooperation: Values and Incentives'. Quarterly Journal of Economics 123(3):905-50.

UNESCO. 2012. Análisis de contexto comunitario en el municipio San Bartolomé Quialana. Technical report UNESCO, Oaxaca.

World Bank. 2012. World Development Report 2012: Gender Equality and Development. Washington, DC: World Bank Group.

Young, Peyton. 2008. 'Social Norms.' In Steven Durlauf and Lawrence Blume (eds), The New Palgrave Dictionary of Economics, 647-651. London: Palgrave Macmillan. 